***This is an earlier version of a paper published in Human Nature, volume 20, no. 1 (2009): pp. 1-24. The original publication is available at www.springerlink.com. ***

\title{
Liberal and Conservative Protestant Denominations as Different Socio-Ecological Strategies
}

\author{
Ingrid Storm (University of Manchester) \\ David Sloan Wilson (Binghamton University)
}

Acknowledgements: Thanks to Mihaly Csikszentmihaly and Barbara Schneider, for sharing their data. To David Voas and Nick Shryane and anonymous reviewers for helpful comments and advice. 


\title{
Liberal and Conservative Protestant Denominations as Different Socio-Ecological Strategies
}

\begin{abstract}
$\underline{\text { Abstract }}$
It is common to portray conservative and liberal Protestant denominations as "strong" and "weak" on the basis of indices such as church attendance. Alternatively, they can be regarded as qualitatively different cultural systems that coexist in a multiple-niche environment. We integrate these two perspectives with a study of American teenagers based on both one-time survey information and the experience sampling method (ESM), which records individual experience on a moment-by-moment basis. Conservative Protestant youth were found to be more satisfied, family-oriented and sociable than liberal Protestant youth, but also more dependent on their social environment, which is reflected in a deterioration of their mood when they are alone. Liberal Protestant youth appear to have internalized values that remain constant in the presence and absence of others. We relate these results to the social scientific literature on liberalism and conservatism and to evolutionary theory as a framework for explaining cultural systems as adaptations to multiple-niche environments.
\end{abstract}




\section{$\underline{\text { Introduction }}$}

Religiosity and denominational affiliation is associated with a number of sociodemographic and attitudinal variables (see for example Greeley and Hout, 2006; Gunnoe and Moore, 2002; Stark, 2002). While there are important exceptions, religiosity in the United States is largely found to be negatively correlated with education, income and social status. Despite a general agreement about such results, the ultimate reasons for and even the causal relations in these correlations remain unresolved.

One of the most intriguing attempts to make sense of these patterns comes from political scientists Norris and Inglehart (2004). They identified strong correlations between degrees of religiosity and socio-economic variables such as levels of poverty, unemployment, education and economic equality, based on analyzes comparing 191 nations worldwide from the longitudinal World Value Survey. The reason they suggest for the variation and growing polarization of religion, is that religiosity and secularism are linked to different "survival strategies" (2004: 23). It should be noted that the word "strategy" is used loosely, referring to aggregate demographic trends rather than conscious decisions on the part of individuals. Rich secular societies produce fewer people, but more is invested in each individual, so that survival into adulthood is almost guaranteed. In contrast, poorer traditional societies have higher fertility rates, but they also have high infant mortality rates and overall death rates (2004: 23). Applying a view of religion as an adaptive strategy, we suggest that different Protestant denominations may be regarded as cultural systems adapted to different niches in the social environment.

Iannacone (1994) identified a strong positive correlation between denominational growth and the "strictness" of religious denominations. The strictness and demands of the denomination also correlated strongly with the levels of religiosity and church attendance of its members. Our hypothesis is that the denominational categories identified by Iannaccone are qualitatively 
different with respect to cultural strategies, and that affiliation with each of them will be reflected in the moral values, behaviours and experiences of the respondents in our sample of American youth. Based on evidence from the social science and psychology literatures, as well as a conceptual framework from evolutionary theory, we expect conservative Protestants to display a greater reliance on external rules and authorities than liberal Protestants, who we expect to show greater levels of autonomy.

\section{Religion as an evolutionary adaptation}

Religion is known to be a nearly universal human phenomenon, but the particular form it takes varies greatly, not only between societies but also within them. As Robert Wuthnow (1988: 308) writes in his sociological account of historical shifts in American religion, "Religion has an organic quality, a communal and moral dimension that binds people to one another and creates close dependencies between them and their environments". From an evolutionary and ecological perspective, one would expect different environmental and social factors to result in different forms and degrees of religiosity, and the social science data largely support this proposition. Political scientists Norris and Inglehart (2004) suggest that the economic growth and demographic transition in modern democracies has led to a new environment in which traditional forms of religion are no longer adaptive. The question is then why they would be adaptive in any environment.

The evolutionary hypothesis advanced by D.S. Wilson $(2002 ; 2005)$ explains religion as an adaptive behavioural phenomenon that has been favoured by natural selection largely operating at the group-level. Religion is regarded as enhancing communication, trust and cooperation, and thus benefiting the community of believers as a whole. The main idea is that religion has been selected for in our evolutionary history because members of religious groups on 
average had a reproductive advantage over members of non-religious groups. This theory can also be used to explain the existence of different religious communities, either as responding to different ecological challenges, or offering different proximate strategies to deal with the same environment. By examining differences in attitudes, values and behaviour between liberal and conservative protestant high school students in the USA, this study addresses the possibility that different religious denominations occupy different niches in the social ecology of human populations.

The conceptual model we use for understanding religious diversity is borrowed from ecology, in that we imagine a social environment with multiple niches. For a species to succeed in any environment it must adapt not only to physical conditions such as climate, altitude and soil composition, but must also find its place among other species in the same environment. For this it needs an ecological "strategy" that gives it opportunity to coexist with these other species, or successfully compete with them over resources. In this model, the religious groups are to be seen as cultural "species" in the sense that they coexist, partly by appealing to different segments of the population, and partly by competing for attention from the same population. The "group" is defined by its individual members' possession of a common trait, and should not be understood as a bounded unit without interactions with other groups. On the contrary, it is precisely its interactions with other groups that define its properties.

The socio-ecological niches are to be understood as different parts of the population, defined by such demographic variables as geography, socioeconomic class, education level, economic sector, age, race, etc. Clearly, the socio-ecological niches overlap greatly with each other, but as Norris and Inglehart's (2004) study indicates, they can nonetheless be useful for understanding the particular cultural strategies that are associated with different kinds of religiosity. The ecological analogy we employ is in many ways similar to the economic theory of 
a religious market developed over the last decade of sociological studies of religion (Iannacone 1994; Stark and Bainbridge 1997; Stark and Finke 2000). Like those who favour the market analogy, we see the religions as appealing to different niches of the population, and serving functions such as improving health and increasing social capital. When we prefer the evolutionary-ecological paradigm it is due to the following advantages. Firstly, evolutionary theory provides a holistic framework for the study of culture that is compatible not only with economic theory but with the process that ultimately is the source of all life forms and cultural expressions. Secondly, rational choice in our model is not privileged as an explanation, but regarded as one among many possible proximate mechanisms for the survival and reproduction of religion (Wilson 2002:76). These mechanisms include processes unconscious to the individual, such as birth rates. Even if individual choice were the primary factor in explaining religious growth and decline, individual rationality, intentionality and preference are themselves attributes evolved through a process of natural selection (2002:74-5). Thirdly, "otherworldly rewards" (Stark and Finke 2000: 88) may be explanatory as a motivation for religious belief and behaviour on a short time scale. Nevertheless, evolutionary theory predicts that any behaviour that incurs more costs than benefits in this world, would lead to decreased fitness and thus have a slim chance of survival over thousands of years.

Despite a reluctance to add to the already abundant collection theoretical frameworks in the social sciences, we do believe that the incorporation of evolutionary theory into the study of religion is an important step towards a holistic study of culture. Particularly significant in this regard is the way it encourages a view of culture in terms of adaptability and survival. These are qualities that normally receive remarkably little attention in the social sciences although most would agree that that they by definition are necessary for the very existence of cultural traditions and groups. 


\section{How does a religion survive?}

The survivability of a religious variant could be said to depend on two main factors.

Firstly, its ability to retain its members and prevent them from dying, leaving or converting to other religions, and secondly, its recruitment of new members through either biological reproduction or proselytizing. Like any demographic process, this can be summarized in two inputs: birth and immigration and two outputs: death and emigration. Since the vast majority of religious recruitment takes place within families, and since the majority of children adopt the faith of their parents or guardians, these survival strategies are closely linked. A successful religion is thus one whose members both maintain their faith, and successfully transmit it to their children. Much has been made of the conservative upsurge in American Protestantism, but as Greeley and Hout (2006:105) have shown, the recent growth in conservative denominations does not reflect conversions from mainline Protestantism, but stems primarily from the higher rate of reproduction in conservative families compared to liberal families. Reproduction rates are higher both literally in the number of children per couple, and figuratively in the number of people who retain their childhood religion into adulthood.

For a religious variant to survive it is thus necessary to adopt a cultural strategy that encourages both kinds of reproduction and adapts it to its local environment. By carving out a social niche, religions may effectively prevent members from converting because the strategy they employ will be unsuited for other niches in the social ecology. One such strategy that might be central to religious difference concerns transmission of information. According to Richerson and Boyd (2005), evolved capacities for "biased cultural transmission" minimize the cost of learning, particularly in risk-filled environments where decisions have to be made quickly. Conformity to the majority view and reliance on authorities, family members and successful members of the community are examples of such adaptive strategies of information acquisition. 
Religion may be seen as a way of facilitating these transmission biases, insofar as it often puts a premium on family values, submission and obedience to authorities. As we will show, the conservative religious model of society encourages a division of labour in which authorities have access to information and do most of the reasoning necessary for decision-making. The majority of the population thus escapes the high costs of independent reasoning by being obedient to the authorities. In contrast, liberal religion tends to emphasize individual independence and responsibility, suggesting a different adaptive strategy catering to a different socio-ecological niche. This niche could for example be a secure and stable environment with opportunities for individual creativity and the development of innovative ideas. The statistical and historical correlations between higher education and liberalism (Greeley and Hout 2006: 98-9; Whutnow 1988:162-3) are not surprising when seen in this light.

In this study of Protestant youth, we integrate the diverse bodies of scholarship on liberal and conservative religion by using an evolutionary model of a multiple-niche environment as the framework for our analysis.

\section{Data and Method}

\section{The Database}

The analysis is based on data from the Sloan study of youth and social development, a longitudinal nation-wide survey conducted by Csikszentmihaly and Schneider (2000) from 1992 to 1997 for the purpose of examining young people's attitudes about education and career-choice. The thoroughness and uniqueness of the study enables it to be used for other purposes (Wilson and Csikszentmihaly 2007). We consider adolescents a particularly interesting group to study from a cultural evolutionary perspective because their age places them in a unique position to determine the future survival of the culture they belong to and practice. Their experiences should 
thus serve as "excellent indicators of possible developing trends in American religion more broadly" (Smith 2005: 6).

Our analysis focuses on year 5 of the study. The sample population came from thirtythree schools (20 middle schools and 13 high schools) in a wide variety of geographical locations and representing students of diverse ethnic and socio-economic backgrounds. In each school, a focal sample $(\mathrm{N}=353)$ and cohort sample $(\mathrm{N}=2852)$ were selected. The focal sample was being followed longitudinally (year 5 being the final year) and the cohort sample was selected anew each sampling period as representative of the school grade in which the focal students were enrolled (Csikszentmihaly and Schneider 2000: 25).

The data collection consisted of a number of one-time questionnaires administered to the cohort and focal samples as well as interviews of focal students, their teachers and parents, and a week of the Experience Sampling Method (ESM). The ESM involves dividing the day into 2hour periods and signaling participants at random once within each period, prompting them to complete a 62-item questionnaire detailing their external circumstances (where they were, what they were doing and who they were with) as well as internal experience (e.g. happiness, sociability, anger, control) on numerical scales. Data from both one-time questionnaires and ESM were used in our analysis. While the former provides information about each student's religious background and a range of variables about family, friends and general attitudes, the latter offers unique insight into the day-to-day experiences of the individual respondents.

\section{Religious categories}

The analysis was restricted to the students who answered that their religious background was Protestant Christian. The reason for this choice was primarily that this questionnaire item distinguished between Protestant denominations, which can be categorized along a continuum 
from liberal to conservative. Iannaccone (1994:1190) grouped protestant denominations into four categories: 1) liberal mainline (Episcopal, Methodist, Presbyterian and the United Church of Christ), 2) moderate mainline (Evangelical Lutheran, Reformed Church, Disciples of Christ and American Baptist), 3) conservatives and evangelicals (Missouri Synod Lutheran and Southern Baptist) and 4) fundamentalists, Pentecostals and sects (Nazarene, Assemblies of God, Seventh Day Adventists, and Mormon). In order to get a large enough sample, we combined the latter two categories as one, which for the sake of simplicity have termed "conservative". For some of our comparisons, we also include students who indicated that they were "non-religious."

(Table 1 about here)

Despite general trends, there are great differences along a liberal-conservative continuum within each denomination. Wuthnow $(1988 ; 1989)$ describes the split between conservatives and liberals within each denomination as frequently greater than between denominations. Stark and Bainbridge (1997: 71) similarly hold that while denominations are decent indicators of religiosity, "(t)here is no point in using proxy variables when direct variables are available". However, we justify our choice of variable with the idea that what matters in an adaptive group is not just individual level of religiosity, but the entire ethos of moral values and behavioural codes. As our results will show, membership in a denominational category and individual level of religiosity are both important variables, but measure quite different things, and thus one cannot easily be substituted for the other. If different denominations are to be seen as different strategies corresponding to different niches in the social environment, we predict that high degrees of religiosity within each denominational culture will have different outcomes. Nevertheless, due to the heterogeneity of the moderate category, most of the analysis focuses only on the liberal and 
conservative categories. Baptist and Lutheran congregations are extremely diverse when it comes to liberalism and conservatism, and since we have no information on the subdenominational categories, we have focused our analysis on the denominations that have been described by Iannaccone (1994) as either liberal or conservative. The non-religious are excluded for similar reasons. This group is highly diverse, and absence of religious affiliation is not considered sufficient basis for classification as liberal or conservative.

Existing categorizations of religion, and of Protestant denominations in particular, often assume that different religious traditions can be aligned along a single continuum, from weak to strong. An example of this is T. W. Smiths (1990) liberalism-fundamentalism scale, the most widely used classification scheme for survey research (Steensland et. al. 2000: 291). That is, conservative and evangelical Protestants are often assumed to be more religious than liberal or mainline Protestants. The alternative, to treat religiosity as a nominal rather than an ordinal variable, "guards against mainline Protestantism being treated as a diluted form of orthodoxy" (2000: 295). At the same time, employing a purely nominal taxonomy requires an alternative conceptualization of the differences between religious denominations. When this is lacking, it may be unclear which criteria for classification are relevant for any particular analysis of denominational affiliation.

In contrast, we suggest applying an evolutionary or ecological framework of analysis, in which different denominations and traditions are understood as qualitatively different "cultural species" in a multiple-niche environment. The advantage of this approach is that it allows for religious traditions to be conceptualized as qualitatively different without necessarily being ranked as stronger or weaker than each other. We have based our denominational categories on a conservative-liberal continuum put forward by Iannaccone (1994). Religious variants such as liberal and conservative Protestantism may be seen as analogous to species distributed along 
gradients of resources and habitat complexity. On the one hand they can be ranked quantitatively along a continuum, but on the other hand their ecological strategies are qualitatively different. We are in other words not suggesting a new classification scheme for religious denominations. Instead we are advocating a new way of understanding existing categories as multidimensional and simultaneously ordinal on some dimensions and nominal in others.

\section{Statistical analysis}

Statistical comparisons were made with analysis of variance (ANOVA), based on sample sizes shown in Table 1. For analysis of the one-time questionnaire items, the sample sizes are straightforwardly the number of conservative (100) and liberal (205) Protestants who completed the questionnaire. For analysis of the ESM data, 11 conservative Protestants responded a total of 277 times and 39 liberal Protestants responded a total of 840 times. In one set of analyzes we used the number of responses as the sample size in comparing the two groups. In another set of analyzes, we calculated average values for each individual and used the number of individuals as the sample size in comparing the two groups. These two sets of analyzes bracket the extremes in terms of assumptions about statistical independence. Because we are summarizing a large number of comparisons, we report the mean values for each group and significance value (p) of the ANOVA, without reporting F-ratios or other statistics. More complete information is available upon request. We do not make Bonferroni or other corrections for multiple comparisons (Harris 2001). In general, the number of comparisons that are statistically significant is far above the 1in-20 that would be expected by chance. 


\section{$\underline{\text { Results }}$}

\section{Liberal individualism and conservative authoritarianism}

Consistent with the social scientific literature and the picture of conservatism and liberalism as adaptations to different socio-economic niches, highly significant correlations were found between the denominational variable and measures of socioeconomic class and the educational level of parents. These associations between religious affiliation and socioeconomic variables are already well established in the literature, but have not before been interpreted from a multiple niche perspective.

(Table 2 about here)

Comparisons between the mean values of the one time questionnaire items using one-way ANOVAs showed significant differences between the groups, particularly on items concerning family values. On average, liberals reported more praise and individual attention from parents and other family members than did conservatives. Examples include items such as "I am made to feel special on birthdays and holidays" and "I receive special attention and help when I have a problem". However, on the questionnaire items concerning parental attention in the forms of rules and regulations, the trend seemed to go in the opposite direction. For example, conservative teens have less influence over what friends they can spend time with. The majority of these correlations were still significant when we controlled for the educational levels of the parents. Taken together, these results show an interesting pattern of strictness combined with little individual attention for conservatives and lenience combined with high levels of individual attention for liberals. 
(Table 3 about here)

\section{Happiness and control}

The results from the one time questionnaire related to students' thoughts about the future revealed another interesting difference between the categories. The conservative students were found to feel secure, in control and optimistic about the future, whereas the liberal students scored significantly lower on most of these variables (Table 4). In contrast, liberals scored higher on items measuring worry and stress. They also scored higher than conservatives on curiosity about the future, which indicates that they see their lives as less predictable. These results were also significant when we controlled for the educational levels of the parents. The feelings of security among conservatives may be a result of stricter rules, and fewer individual responsibilities.

(Table 4 about here)

\section{Moment-by-moment differences}

Although interesting in their own right, these results are even more meaningful when viewed in light of the data obtained by the Experience Sampling Method (ESM). Just as in the one time questionnaire, the ESM data reveal a highly significant general tendency for conservative Protestants to be happier and more at ease than liberal Protestants on a moment-by-moment basis.

(Table 5 about here) 
The different value systems of liberals and conservatives are likely to be reflected in the amount of time spent alone and the quality of individual experience when alone vs. in the presence of others. As shown in Figure 1, liberals spend 26\% time alone compared to $17.5 \%$ for conservatives, a considerable difference given that American high school students don't have much discretionary time in which they can be alone

(Fig. 1 around here).

Even more impressive are the differences in experience when alone vs. in the presence of others, as shown in Figure 2 a-e. When they are alone, Conservatives are considerably more lonely (Fig. 2a), more bored (Fig. 2b), wished they were doing something else (Fig. 2c), were less angry (Fig. 2d), weaker (Fig. 2e), and more self-conscious (Fig. 2f) than when they are in the presence of others. The experience of liberals was more constant in the presence and absence of others and, they frequently preferred to be alone. These very strong interaction effects illustrate that the conservative and liberal value systems are qualitatively different, as opposed to having merely quantitative differences that can be conceptualized in terms of "weak" and "strong."

(Figure 2a-e about here)

The results shown in Figure 2a-e treat single ESM responses as the unit of analysis. In other words, we have so far assumed statistical independence of responses coming from the same individuals. In order to test whether we would get similar results using individual respondents as the unit of analysis, we repeated the ANOVA for the significant results comparing the difference between the variables' mean values when alone and not alone for each of the 11 conservatives and 39 liberals (see Table 1). In order to get an adequate frame of comparison between the 
individuals' experiences of being alone and not alone, we excluded from analysis those who responded to less than seven ESM questionnaires (ten liberals) as well as three individuals (two conservatives and one liberal) who never reported being alone. As expected, due to the small sample size, the results from this analysis were on average less significant than the original analysis based on responses. However, four differences out of nine were still significant, notably Excited - bored $(\mathrm{P}=0.0366), \underline{\text { Strong }- \text { weak }}(\mathrm{P}=0.0178)$, Sociable - lonely $(\mathrm{P}=0.0146)$ and $\underline{\text { How }}$ angry did you feel? $(\mathrm{P}=0.0052)$ For these four variables conservative individuals displayed much larger differences than liberals between being alone and not alone

In order to get a clearer picture of who it is conservatives spend time with that makes them feel better than liberals when they are not alone, we separated the "not alone" category between time spent with friends and time spent with family members (See Figure 1). When looking at results for interactions with time spent with friends and time spent with family, the latter seems to have the larger effect on the variables that were significant for "alone" (See Table 6). In spite of their receiving relatively little positive attention from their families, conservative Protestant students spend much more time with them: $27 \%$ of the time, compared to only $13 \%$ of the time for liberals. They also feel much better on average when they are with family members than when they are not (Figure 6).

By contrast, being with friends seems to have a relatively greater impact on liberals than it has on conservatives. For example, liberals were significantly less lonely when in the company of friends although they generally varied little in the mean values of sociability/loneliness across social contexts. When they were with relatives, the liberal teens were slightly more lonely than when they were with friends or other non-relatives. Conversely, conservatives were much more sociable in the company of both relatives and friends than when they were alone or with others (Figure 6). The general ESM results for feeling strong/weak were similarly better explained by 
time spent with relatives than with non-relatives. Conservatives felt stronger in all kinds of company than when they were alone, and being with relatives had the largest positive effect on their feeling of strength. In contrast, friends were the only kind of company that had a marginal effect on this variable on liberals. The general result for succeeding in what they were doing appears to be influenced by the presence of both friends and relatives, whereas anger and living up to the expectations of others seems to mainly be the result of time spent with friends (Figure 6). Surprisingly, there were no significant results for interactions with time spent with either friends or relatives for self-consciousness and embarrassment, excitement and boredom or wishing to be somewhere else. Most of the other results showed both friends and family to have positive effects (Figure 6). Overall, friends seem to have a stronger effect on liberals, whereas family has a larger effect on conservatives.

(Table 6 about here)

To summarize, despite the differences in family cultures found in the one time questionnaire, both liberals and conservatives seem to appreciate the company of family members, although to a somewhat different degree. To examine the importance of family more closely, we looked for additional interaction effects in the one-time questionnaire items

\section{Stress and independence}

Correlations between parental restrictions and stress, measured by two-factor analysis of variance between the items "In my family, I am the one to decide which friends I can spend time with" and "Do you usually feel stressed?", show that liberals are more stressed when they are not allowed to make decisions about their own social lives (See Figure 3). No such correlation was 
found for conservatives. Being raised in a liberal culture appears to makes the teenagers feel like they need to be in control over their own lives in order to be happy and relaxed. Conservatives on the other hand expect to be restricted and to comply with authorities to a greater degree and for most of them this does not make them feel stressed or lacking in control. Ironically then, liberal teenagers, who are objectively more in control of their lives than conservatives, feel as if they are less in control. This finding is consistent with the theoretical literature on conservatism and liberalism, which suggests that parental values are easily internalized (Boshier 1973: 222; Jost 2003: 347). Thornhill and Fincher (2007) have suggested that liberal ideology may be a risktaking strategy adopted in reaction to childhood stressors and insecure attachments. However, the results in Figure 3 indicate that stress is experienced as a result of a liberal orientation rather than the other way around.

(Figure 3 about here)

To further the hypothesis that conservatism and liberalism are qualitatively different systems rather than simply points on a scale of religiosity, we looked at the correlations between religiosity and various measures of family values and strictness for each religious group. The item "In my family, we express different opinions even when they differ" is indicative of liberal values. Figure 4 shows that agreement with this item correlates positively with religiosity for teens from liberal denominations and negatively for teens from conservative denominations, suggesting that the denominations are inculcating substantially different values. Conservatives who scored high on the religiosity variable responded that their families express differing opinions less often than conservatives who scored low on religiosity. Liberals display the exact opposite trend. In other words, for the liberal Protestants, religiosity is correlated with some 
forms of personal autonomy and liberalism, whereas for conservatives it is correlated with strictness and authoritarianism. Liberal and conservative religiosity are pulling the youth in opposite directions.

(Figure 4 about here)

To further explore these results, we constructed a "liberal family scale" based on five items about family values from the one time questionnaires that significantly correlated with the liberalconservative distinction (See Figure 5). This was done in order to measure liberal and conservative family values for individuals, regardless of their religious denomination. To clarify, the usage of the term "liberal" in this scale (Figure 5) refers not to the religious denomination, but to the particular attitudes and practices of the family.

When measuring the ESM variables against the liberal family scale, a remarkable pattern emerged, revealing that conservative protestants feel weaker, more stressed, less happy, less interested, less hopeful and less good about themselves the more liberal their families are (Figure 5). In contrast, liberal protestants, when it makes a difference to them at all, tend to feel better the more liberal their families are. Figure 5a-c are only examples of these results. The higher the score on the liberal family scale $(0-100 \%)$, the more liberal the family is according to the questionnaire items below.

(Figure 5 a-c about here)

Just like personal religiosity, liberal family values appear to have different effects depending on denominational group. This shows that there is an important distinction to be made between 
individual measures and group measures of belief and ideology. By itself the liberal family scale appears insufficient to explain the full range of differences between the "liberals" and "conservatives". Rather, the effects on the individual teenagers' experience cannot be divorced from either their personal religiosity or their family values, which are presumably sustained in part by the larger religious community.

\section{$\underline{\text { Discussion }}$}

\section{Conservative and liberal strategies}

As indicated by Table 2, liberal Protestantism is positively correlated with class and education in our sample. This is consistent with Iannaccone's (1994: 1193, 1199, 1201) findings as well as most other studies of American religion (see for example Greeley and Hout 2006: 98-100). Moreover, the negative association between conservative religiosity and socioeconomic class may be described as a global phenomenon (Norris and Inglehart 2004: 69-70). By viewing religion as a reaction to existential uncertainty, Norris and Inglehart (2004) suggest that the security and wealth provided by the modern welfare state, particularly in Northern Europe, has the effect of promoting secularization by limiting the need for religion as a system of organization and cultural transmission. Jost et. al. (2003: 365) point to a number of studies indicating that conservative attitudes to religion and politics are strongly correlated with uncertainty and stress. In periods of severe economic threat, such as the depression years (193039), more people joined conservative churches such as Southern Baptists and Seventh-Day Adventists and less joined more liberal churches compared to periods of relative prosperity. Moreover, psychological experiments have shown that priming people to think about their own death causes them to express more conservative attitudes than people who had not been reminded of their own mortality (2003: 349). Following simple rules and avoiding uncertainty and 
ambiguity may facilitate more rapid decision making in certain environments, and are likely to have been adaptive cognitive mechanisms in our evolutionary history. In a variety of studies reviewed by Jost et. al. (2003) intolerance of ambiguity, need for cognitive closure and general preferences for the simple and familiar over the complex and unknown have been shown to correlate strongly with social conservative attitudes and beliefs. This supports the hypothesis that religious conservatism may be seen as a cognitive and behavioural strategy adapted to deal with situations of threat and uncertainty.

However, religion comes in a variety of forms, and we make the claim that conservative authoritarianism is but one strategy that religion may provide. Just as natural environments consist of many ecological niches that require different strategies of survival and reproduction, so different social environments should foster different cultural and religious systems. In other words, we postulate that environments of stability, security and wealth will cause a different form of religiosity to thrive, that is liberal religion. Liberal religious people in our model are not necessarily "less religious" (although on average they do rate themselves less religious (Table 2)), but their religion has different consequences for their moral values and behaviour than conservative religion. Rather than being placed on a scale from "weak" to "strong", liberal and conservative religions are seen as qualitatively different socio-ecological strategies.

\section{Different experiences of control}

Our data indicates that conservative students are subject to external control in the form of social constraints on their behaviour as well as their beliefs. Combined with strong social support, this may serve to make the teenagers feel secure and in control of their lives. They know what is expected of them, and what they can expect from their social environment. In contrast, liberal Protestants seem to have a culture that is more focused on internal control. The students in this 
group are on average more self-reliant and seem to be encouraged by their families to make independent choices rather than adhering to strict rules.

These differences are consistent with the literature on conservative and liberal psychology. In characterizing what he sees as the core tenets of conservative and liberal morality, Lakoff (1996) distinguishes between two different family models, the conservative "Strict Father Model" and the liberal "Nurturant Parent Model". While the former emphasizes obedience and adherence to rules, the latter is more concerned with developing the individual potential of each child, encouraging curiosity and independent thought. It is easy to imagine that such a family will thrive when the number of children are limited so that the parents have plenty of time and resources to allocate to each of them. Conversely, in situations of insecurity, threat and lack of resources, the Strict Father model is an efficient and much less costly way of ensuring order and stability. These different models of parenting and moral reasoning have been found to correlate strongly with both political and religious attitudes associated with liberalism and conservatism (Lakoff 1996; Altemeyer 1988; Jost 2003). Many of the general ESM results that showed conservatives as happier, more excited and less lonely than the liberals, could be accounted for by the fact that conservatives spend less time alone. However, the results also show that spending more time with other people may not be the optimal solution for students in the liberal group. Different experiences of loneliness and sociality are related to more than just the presence or absence of company, and seem to have internalized cultural roots.

The results from Table 4 show conservatives feeling more in control and less uncertain about the future. A liberal culture with heavy emphasis on individual decision making leaves more possibilities open for the child, and may produce feelings of insecurity and lack of control. To see this manifest itself in different stress levels between different denominations among similarly aged members of the same major religion and nationality is a remarkable point in favour 
of the hypothesis that these are different cognitive systems. While conservatives are comfortable relying on the demands of external authorities, the same restrictions produce feelings of stress in liberals. As Eileen Barker (1996: 59) puts it, "while some may find an increased freedom within a cage, others may find themselves increasingly caged by the very pursuit of freedom". The value of independence as freedom, despite its prevalence in mainstream American culture, seems to be peculiar to the more liberal denominations. Greeley and Hout's (2006) study of happiness in marriage, showed that $70 \%$ of conservative Protestants who accept emotional interdependence in marriage report that they are happy, compared with only $57 \%$ of those who describe their marriage as emotionally independent. In contrast, 58\% of mainline Protestants were happy in their marriage, regardless of whether they were independent or not (2006: 142). This result echoes the tendency we found for dependence on family members to be valued among conservatives but not liberals.

Following established rules may take the burden off the individual to make constant life choices, and thus reduce both the stress of decision making and the risk of taking a wrong step. Social control in the form of surveillance and punishment prevents the transgression of moral norms, and empirical evidence indicates that belief in supernatural agents may have the same effect (Johnson and Bering 2006). The success of such strategies however, depends on the support network of other committed individuals, and hence stress may actually increase when a conservative finds himself alone or lacking the company of other group-members. Similarly, as the liberal family scale indicates, conservatives seem to fare worse than liberals when they are in environments marked by liberal attitudes. The results have shown how conservatives seem to gain confidence and happiness from the predictable hierarchy and norms of the family. While authority, duty and tradition are important moral concepts from a group-perspective, they are less valued and may even be seen as immoral from the point of view of an individual-centred morality 
(Haidt and Joseph 2008: 7; 24). These differences in morality may partly explain why liberals seem to prefer the company of friends over family and value the presence of family members less than conservatives.

As already mentioned, personal choice and interpersonal relations are not the only factors to consider when studying religion. The greater reliance on literal interpretations of scripture (Greeley and Hout 2006: 15) and higher frequency of prayer (2006: 24) among conservatives may reflect the same cultural strategy of dependence on others, be they human or supernatural. Schieman et. al. (2006: 540) found that a sense of divine control was strongly negatively correlated with socioeconomic status among elders, and they also found that blacks on average had a stronger sense of divine control than whites. This suggests that persons who experience greater disadvantage and stress by their socioeconomic and racial status choose to place more control in the hands of an external authority. This may be a reaction to existential insecurity as suggested by Norris and Inglehart (2004), and may be regarded as a cost-reducing strategy of decision-making as well as a way of increasing security through tight social networks associated with strongly devoted religious groups.

\section{Anger and authoritarianism}

The great differences in levels of boredom and loneliness for conservatives when alone vs. with others indicate a higher level of dependency on others, or possibly a stronger ability to benefit from company. Against this background, the result that conservatives tend to be angrier than liberals in the company of others appears paradoxical. One interpretation is that conservatives may be more easily moved to anger when they find themselves in disagreement with their friends. Altemeyer's Right-wing Authoritarianism (RWA) scale correlated moderately with measures of aggression (Altemeyer 1988: 108), and a common interpretation is that because 
high-RWA's or conservatives are generally more rule bound, they have a lower tolerance for deviance and norm-bending behaviour than low-RWAs, and thus respond more readily with aggressive punishment. Liberals may have higher tolerance than conservatives for individual differences in opinion, attitude and behaviour, due to being raised in a cultural environment that emphasizes tolerance and respect for diversity. If so, a liberal would be more flexible and accommodating, and not as easily angered with peers who display different values than themselves.

From an evolutionary perspective, this result may be related to the concept of "altruistic punishment". Punishment for deviance may be considered beneficial for a community insofar as it helps maintain social norms and standards. Because administering punishment is costly for the individuals who punish as well as those being punished, such acts can be described as altruistic. Simply put, "people who help to maintain cooperation by punishing cheaters are benefiting others at their own expense" (O'Gorman, Wilson and Miller 2005: 375). High levels of aggression and intolerance among conservatives may be a result of cultural norms which place value upon altruistic punishment. In contrast, a liberal laissez-faire attitude to deviance may be less costly for the individual, but could have negative consequences for the group as a whole. It is thus worth noting that conservatives are only more angry than liberals when they are with friends and family. When in the company of people who are neither friends nor family, liberals are significantly angrier than conservatives. That conservative anger is primarily directed towards ingroup members, is exactly what one would expect of altruistic punishment. In this case, liberal and conservative morals and attitudes to norm-bending may thus be described as alternative strategies for dealing with the classic public goods dilemma of group fitness versus individual fitness (O'Gorman, Wilson and Miller 2005: Sober and Wilson 1998: 145-146). 


\section{The importance of religious identity}

Another important finding is that the strongly religious liberals emerge as a particularly welladjusted group of students. They seem to receive mainly positive attention from their families and enjoy a great degree of autonomy, while at the same time feeling secure and happy.

This is consistent with the findings of John Evans (2003) in his study of membership decline in Presbyterian denominations. His conclusion was that "in states where PCUSA members are simultaneously creating identities as both orthodox Christians and (relative) theological liberals the membership is declining the least" (Evans 2003: 474).

Both strong religious beliefs and a strong social identity seem to be characteristic of the most thriving religious communities. According to Evans (2003), it matters less whether the beliefs are theologically conservative or liberal than the degree to which they contribute to the creation and preservation of a unique identity. This can be achieved by drawing boundaries against other religious and non-religious groups through different beliefs and practices. Strictness is but one way of drawing such boundaries, but it appears to be a particularly effective one for many conservative congregations (Kelley 1977).

The differences between conservatives and liberal protestants described in this paper are clearly instrumental in the construction of cultural identities, not least because it enables an opposition to a defined "other". In a national survey conducted in 1984, religious liberals described religious conservatives as "rigid, intolerant and fanatical" while religious conservatives viewed religious liberals as "shallow, morally loose, unloving and unsaved" (Whutnow 1989: 24). There is in other words not only a popular awareness of the liberal-conservative distinction, but those who identify with these labels often do so through negative stereotypes of the opposition. Clearly, these students' identifications are numerous and complex, and this is not an effort to reduce their social identity to a question of denominational affiliation. Nevertheless, 
religious identities may partly account for the significant positive correlations between religiosity and positive affect. A plausible explanation for the difference in sociability and loneliness may be that the 'need to belong' (Baumeister and Leary 1995) is on average better fulfilled by conservative Protestantism than by the other religious categories. The higher levels of church attendance and time spent with relatives indicate a fostering of closer family connections and more social contact with other congregation and community members.

\section{Limtations and possible criticisms}

A possible problem with the data is that the scales used in the ESM questionnaire asks for the students to rate their feelings on a continuum from happy to sad, lonely to sociable etc. Unfortunately this forecloses the possibility that one person may be feeling for example sociable and lonely at the same time. However, while this problem may be an obstacle to the interpretation, it does not diminish the fact that we found significant differences between the religious groups on these variables.

Like all analysis of this type, this one also suffers from the problems of defining causal direction. For example one could discuss whether the differences we have found between liberal and conservative Protestants are the result of their different cultural upbringings, or whether their affinity with certain denominations is the result of certain personal attributes which produce the results. However, we believe the formulation "religious background" is sufficient to control for these reverse effects, and point to the culture in which the teenager has been raised rather than any religious belief she may have chosen for herself.

Finally, the small sample sizes in the ESM study is unfortunate because the differences between the groups may result from other spurious factors particular to these individuals. Establishing the representativity of the ESM results thus requires further research.. Because of the 
thoroughness in which each individual is examined, experience sampling may be thought of as a quantification of qualitative analysis rather than standard survey research. As such, the small ESM sample of liberals and conservatives supports the results and enhances the analysis the larger quantitative study. It also gives an indication of the details in the relationships between religious denomination and daily experience of life.

\section{Conclusion}

Protestant denominations are commonly found to correlate with a number of social and demographic variables. In the perspective of cultural evolutionary theory, the religious landscape may be seen as analogous to an ecological system where each religious group occupies its own niche. The variation in social practices and attitudes towards family and child rearing indicated by the results of this study of Protestant youth may be seen as examples of how different socioecological niches correspond to different strategies of living. If this were a useful way of thinking about culture in general and religion in particular, one would expect different religious systems to succeed in different social environments and different individual qualities and personalities to thrive in different religious denominations.

The main hypothesis was that Protestant youth from conservative denominations should display a greater reliance on external rules and authorities, and lower levels of individualism than youth from liberal Protestant denominations. This was supported by data both from the one-time questionnaire and ESM. The conservative Protestant teenagers were shown to spend considerably less time alone and more time in the company of family, and their experience of the situation was on average more positive when they were with others. The results of this study indicate that liberal Protestantism is an adaptive cultural strategy in groups of resourceful individuals in secure 
environments. Conservative Protestantism seems to be more adaptive at the group level in situations and environments with comparatively lower existential security.

It is important to emphasize that according to evolutionary theory there is no inherently superior cultural system. What is adaptive varies both in respect to environmental factors, the presence of other religious groups as well as the attributes and personalities of the individuals who make up the group. Our approach predicts that those individuals who succeed in a conservative Protestant community might not do as well if adopting a secular lifestyle. The analysis indicates that "liberal" and "conservative" Protestant cultures produce radically different values, behaviours and feelings in their members. Combined with the observation that liberal and conservative denominations attract members from different socio-economic strata, this offers evidence in favour of the view that conservative and liberal religions may be seen as different socio-ecological strategies in a multiple niche environment. This approach ought to be useful, not only for the study of religion, and may also be applied to ideologies and cognitive systems more generally. 


\section{$\underline{\text { References }}$}

Altemeyer, B. (1988). Enemies of Freedom: Understanding Right-Wing Authoritarianism. San Fransisco: Jossey-Bass Publishers.

Barker, E. (1996). The Freedom of the Cage. Society 33(3): 53-59.

Baumeister, R F. \& Leary, M. R.. 1995. The Need to Belong: Desire for Interpersonal Attachments as a Fundamental Human Motivation. Psychological Bulletin 117(3): 497529.

Boshier, R. W. (1973). Conservatism Within Families: A Study of the Generation Gap. In G. D. Wilson (Ed.), The Psychology of Conservatism, (pp. 209-224). London: Academic Press.

Csikszentmihaly, M. \& Schneider, B. (2000). Becoming Adult: How Teenagers prepare for the world of work. New York: Basic Books.

Evans, J. H. (2003). The Creation of a Distinct Subcultural Identity and Denominational Growth. Journal for the Scientific Study of Religion 42(3): 467-477.

Greeley, A. M. \& Hout, M. (2006). The Truth About Conservative Christians: What They Think and What They Believe. Chicago and London: University of Chicago Press.

Haidt, J. \& Joseph, C. (2008). The moral mind: How five sets of innate intuitions guide the development of many culture-specific virtues, and perhaps even modules. In P. Carruthers, S. Laurence \& S. Stich (Eds.), The Innate Mind, Vol. 3: Foundations and the Future (pp.367-391). Oxford: Oxford University Press.

Harris, R. J. (2001). A Primer of Multivariate Statistics $3^{\text {rd }}$ edition. Mahwah, NJ: Lawrence Erlbaum Associates.

Iannaccone, L. R. (1994). Why Strict Churches Are Strong. American Journal of Sociology 99(5): 1180-1211. 
Johnson, D. D. P. \& Bering, J. M. (2006). Hand of God, mind of man: punishment and cognition in the evolution of cooperation. Evolutionary Psychology 4: 219-233.

Jost, J.. T., Glaser, J., Kruglanski, A. W. \& Sulloway, F. J. (2001). Political Conservatism as Motivated Social Cognition. Psychological Bulletin 129(3): 339-375.

Kelley, D. M. (1977). Why Conservative Churches are Growing: A Study in Sociology of Religion. San Fransisco: Harper \& Row.

Lakoff, G. (1996). Moral Politics: What Conservatives Know that Liberals Don't. Chicago: University of Chicago Press.

Norris, P. \& Inglehart, R. (2004). Sacred and Secular: Religion and Politics Worldwide. Cambridge: Cambridge University Press.

O’Gorman, R., Wilson, D. S. \& Miller, R. R. (2001). Altruistic punishing and helping differ in sensitivity to relatedness, friendship, and future interactions. Evolution and Human Behaviour 26: 375-387 .

Richerson, P. J. \& Boyd, R. (2005). Not By Genes Alone. Chicago and London: The University of Chicago Press.

Schieman, S., Pudrovska, T., Pearlin, L. \& Ellison, C. (2006). The Sense of Divine Control and Psychological Distress: Variations Across Race and Socioeconomic Status. Journal for the Scientific Study of Religion 45(4): 529-549.

Smith, T. W. (1990). Classifying Protestant Denominations. Review of Religious Research 31: 225-45.

Smith, C. (2005). Soul Searching: The Religious and Spiritual Lives of American Teenagers. Oxford: Oxford University Press.

Sober, E. \& Wilson, D. S. (1998). Unto Others: The Evolution and Psychology of Unselfish Behavior. Cambridge, MA: Harvard University Press. 
Stark, R. \& Bainbridge, W. S. (1997). Religion, Deviance and Social Control. New York: Routledge.

Stark, R \& Finke, R. (2000). Acts of Faith: Explaining the Human Side of Religion. Berkeley: University of California Press.

Steensland, B., Park, J. Z., Regnerus, M. D., Robinson, L. D., Wilcox, W. B. \& Woodberry, R.D. (2000). The Measure of American Religion: Toward Improving the State of the Art. Social Forces 79(1): 291-318.

Thornhill, R. \& Fincher, C. L. (2007). What is the relevance of attachment and life history to political values? Evolution and Human Behavior 28:215-222.

Wilson, D. S. (2002). Darwin's Cathedral: Evolution, Religion and the Nature of Society. Chicago and London: University of Chicago Press.

Wilson, D. S. (2005). Testing major evolutionary hypotheses about religion with a random sample. Human Nature 16(4): 382-409.

Wilson, D. S. and Csikszentmihaly, M. (2007). Health and the Ecology of Altruism. In S. G. Post (Ed.) Altruism and Health: Perspectives from Empirical Research (pp. 314-331). Oxford: Oxford University Press.

Wuthnow, R. (1988). The Restructuring of American Religion. Princeton, NJ: Princeton University Press.

Wuthnow, R. (1989). The Struggle for America's Soul. Grand Rapids, MI: Eerdmans. 


\begin{tabular}{|l|l|l|l|l|}
\hline \multicolumn{2}{|l|}{ TABLE 1: Denominational categories and sample sizes } \\
\hline Category & Denominaton & $\begin{array}{l}\text { N (one time } \\
\text { questions) }\end{array}$ & $\begin{array}{l}\text { N (ESM) } \\
\text { individuals }\end{array}$ & $\begin{array}{l}\text { N (ESM) } \\
\text { responses }\end{array}$ \\
\hline Non-religious & 370 & - & - \\
\hline Liberal & $\begin{array}{l}\text { Methodist, Presbyterian, } \\
\text { Episcopalian }\end{array}$ & 205 & 39 & 840 \\
\hline Moderate & Baptist, Lutheran & 537 & - & - \\
\hline Conservative & Pentecostal, Mormon & 100 & 11 & 277 \\
\hline
\end{tabular}




\begin{tabular}{|c|c|c|c|c|c|c|}
\hline & Non-rel & Lib. & Mod. & Cons. & $\mathbf{p} \leq$ & $\mathbf{r}$ \\
\hline How often attended $r$ & 2.11 & 3.48 & 3.83 & 4.64 & 0.0001 & 0.542 \\
\hline Think of yourself as religious & & 1.96 & & & & .502 \\
\hline How far in & 3. & 4.44 & 3.21 & 3.08 & 0.0 & 0.259 \\
\hline How far in school did your mother go? & 3.54 & 4.18 & 3.27 & 3.06 & 0.0001 & 0.206 \\
\hline Social class of the community & 2.86 & 3.20 & 2.67 & 2.55 & 0.0001 & 0.214 \\
\hline
\end{tabular}

Table 2: Religious service attendance on 6-point scale, $1=$ never attends, $6=$ attends more than once a week,

Religiosity on 3 point scale, $1=$ not at all religious, $3=$ very religious, Education level on 7 point scale, $1=$ did not graduate from high school, $7=\mathrm{PhD}$, Social class on 5 point scale, $1=$ poor, $5=$ upper class 


\begin{tabular}{|c|c|c|c|c|}
\hline In my family, ... & Lib. & Cons. & $p \leq$ & $\mathbf{r}$ \\
\hline $\begin{array}{l}\text { I am the one to decide which friends I can spend } \\
\text { time with }\end{array}$ & 4.51 & 3.90 & 0.0001 & 0.246 \\
\hline I am the one to decide whether I can date? & 4.13 & 3.38 & 0.0001 & 0.242 \\
\hline I am made to feel special on birthdays and holidays & 0.79 & 0.62 & 0.0013 & 0.191 \\
\hline We express opinions even when they differ & 0.80 & 0.67 & 0.0172 & 0.143 \\
\hline I get special attention and help if I have a problem & 0.56 & 0.42 & 0.0254 & 0.133 \\
\hline
\end{tabular}




\section{TABLE 4: The Future - mean values by denominational group}

\begin{tabular}{|c|c|c|c|c|}
\hline \multicolumn{5}{|c|}{ TABLE 4: The Future - mean values by denominational group } \\
\hline & Lib. & Cons. & $\mathbf{p} \leq$ & $\mathbf{r}$ \\
\hline $\begin{array}{l}\text { In the future, life will turn out better for you than it } \\
\text { has for your parents? }\end{array}$ & 3.75 & 4.04 & 0.0148 & 0.147 \\
\hline $\begin{array}{l}\text { In the future, your children will have a better life than } \\
\text { you had? }\end{array}$ & 3.73 & 4.23 & 0.0001 & 0.236 \\
\hline Do you feel confident about the future? & 3.85 & 4.12 & 0.0203 & 0.138 \\
\hline Do you feel prepared for the future? & 3.46 & 3.74 & 0.0271 & 0.132 \\
\hline Do you feel worried about the future? & 3.29 & 3.02 & 0.0437 & 0.121 \\
\hline Do you feel curious about the future? & 4.29 & 4.00 & 0.0110 & 0.151 \\
\hline Do you usually feel stressed? & 3.12 & 2.75 & 0.0393 & 0.142 \\
\hline
\end{tabular}

Table 4: All items were on a 5-point scale, with 5 indicating strong positive agreement 


\section{TABLE 5: General ESM results - mean values by denominational group}

\section{Conservatives $>$ Liberals}

Was this activity important to you? (9)

Was this activity interesting? (9)

Was this activity important to your future goals? (9)

How angry did you feel? (9)

Did you enjoy what you were doing? (10)

Did you feel good about yourself? (10)

Did you expect to get what you wanted easily? (10)

Did you feel in control of the situation? (10)

Happy (7) - Sad (1)

Strong (7) - Weak (1)

Sociable (7) - Lonely (1)

Proud (7) - Embarrassed (1)

Excited (7) - Bored (1)

Clear (7) - Confused (1)

Relaxed (7) - Worried (1)

Cooperative (7) - Competitive (1)

Hopeful (7) - Discouraged (1)

Alert (7) - Tired (1)

Liberals > Conservatives

Challenges of the activity (9)

Your skills in the activity (9)

How difficult did you find this activity? (9)

Were you succeeding at what you were doing? (9)

Did you wish you had been doing something else? (9)

Were you living up to the expectation of others? (10)

Did you feel not self-conscious or embarrassed? (10)

\begin{tabular}{crcc} 
Lib. & Cons. & $\mathbf{p} \leq$ & $\mathbf{R}$ \\
5.54 & 6.24 & 0.0002 & 0.115 \\
4.72 & 5.63 & 0.0001 & 0.142 \\
3.84 & 5.43 & 0.0001 & 0.222 \\
1.87 & 2.15 & 0.0623 & 0.059 \\
6.23 & 7.20 & 0,0001 & 0.142 \\
7.77 & 8.57 & 0,0001 & 0.157 \\
6.03 & 6.84 & 0,0001 & 0.129 \\
7.39 & 7.86 & 0,0086 & 0.082 \\
4.79 & 5.30 & 0,0001 & 0.162 \\
4.41 & 5.11 & 0,0001 & 0.234 \\
4.72 & 4.91 & 0,0791 & 0.054 \\
4.44 & 5.19 & 0,0001 & 0.289 \\
4.07 & 4.46 & 0,0011 & 0.101 \\
4.66 & 5.30 & 0,0001 & 0.170 \\
4.53 & 5.21 & 0,0001 & 0.178 \\
4.28 & 4.61 & 0,0006 & 0.107 \\
4.45 & 5.01 & 0,0001 & 0.182 \\
3.60 & 4.25 & 0,0001 & 0.149 \\
Lib. & Cons. & $\mathbf{p} \leq$ & $\mathbf{R}$ \\
4.01 & 3.57 & 0.0322 & 0.067 \\
7.15 & 6.48 & 0.0001 & 0.126 \\
3.71 & 3.01 & 0.0003 & 0.114 \\
7.31 & 7.05 & 0.0806 & 0.055 \\
5.23 & 5.05 & 0.4032 & 0.026 \\
7.32 & 5.69 & 0.0001 & 0.254 \\
9.14 & 8.06 & 0.0001 & 0.209 \\
\hline $10-p 014$ & &
\end{tabular}

Table 5: Word pair opposites on a 7-point scale. All other items on a 9- or 10-point scale with 9 and 10 indicating strong positive agreement. 


\begin{tabular}{|c|c|c|c|c|c|c|c|c|}
\hline \multirow[b]{2}{*}{ Conservatives > Liberals } & \multicolumn{2}{|c|}{ Alone } & \multicolumn{2}{|c|}{ Friends } & \multicolumn{2}{|c|}{ Family } & \multicolumn{2}{|c|}{ Others } \\
\hline & Lib & Cons & Lib & Cons & Lib & Cons & Lib & Cons \\
\hline Activity important (9) & 5.75 & 6.38 & 5.42 & 6.24 & 5.44 & 6.71 & 5.48 & 6.32 \\
\hline Activity interesting (9) & 4.52 & 5.31 & 5.06 & 6.09 & $4.74 *$ & $5.35 *$ & 4.47 & 4.90 \\
\hline Activity important to future goals(9) & 3.56 & 5.52 & 3.80 & 5.88 & 2.82 & 5.13 & 4.69 & 5.68 \\
\hline Angry (9) & $2.07 * *$ & $1.29 * *$ & $1.77 * *$ & $2.66 * *$ & 1.73 & 2.05 & $1.95 *$ & $1.54^{*}$ \\
\hline Enjoy activity (10) & 6.39 & 7.36 & $6.58 * *$ & $7.03 * *$ & 6.83 & 8.16 & $5.14^{*}$ & $6.95^{*}$ \\
\hline Feel good about self (10) & 7.42 & 8.26 & 8.06 & 8.86 & $8.06 *$ & $9.34 *$ & 7.39 & 8.38 \\
\hline Expect to get what you wanted (10) & 5.95 & 7.76 & 6.03 & 6.78 & 6.72 & 7.33 & 5.37 & 6.63 \\
\hline Feel in control of the situation (10) & 7.72 & 8.86 & 7.22 & 7.78 & 7.68 & 8.14 & 6.97 & 7.68 \\
\hline Happy (7) - Sad (1) & 4.63 & 5.07 & 5.00 & 5.48 & $4.77 *$ & $5.68 *$ & 4.74 & 5.10 \\
\hline Strong (7) - Weak (1) & $4.29 * *$ & $4.59 * *$ & 4.62 & 5.42 & $4.31 * *$ & $5.56 * *$ & 4.37 & 5.00 \\
\hline Sociable (7) - Lonely (1) & $4.03 * *$ & $3.38^{* *}$ & 5.32 & 5.73 & $4.55^{*}$ & $5.22 *$ & 4.76 & 4.56 \\
\hline Proud (7) - Embarrassed (1) & 4,28 & 4.88 & 4.60 & 5.39 & 4.50 & 5.45 & 4.42 & 4.95 \\
\hline Excited (7) - Bored (1) & $4.16^{* *}$ & $3.74 * *$ & 4.25 & 4.88 & 4.47 & 4.90 & 3.59 & 4.02 \\
\hline Clear (7) - Confused (1) & 4.57 & 5.38 & 4.86 & 5.66 & 4.87 & 5.59 & 4.47 & 4.68 \\
\hline Relaxed (7) - Worried (1) & 4.64 & 5.14 & 4.56 & 5.15 & $4.61 * *$ & $5.81 * *$ & 4.28 & 4.51 \\
\hline Cooperative (7) - Competitive (1) & 4.15 & 4.38 & 4.20 & 4.54 & $4.28 *$ & $4.97 *$ & 4.53 & 4.78 \\
\hline Hopeful (7) - Discouraged (1) & 4.40 & 4.88 & 4.64 & 5.21 & $3.59 *$ & $4.73 *$ & 4.28 & 4.68 \\
\hline Alert (7) - Tired (1) & 3.34 & 3.70 & 3.85 & 4.37 & 3.59 & 4.73 & $3.41 *$ & $4.63^{*}$ \\
\hline Liberals > Conservatives & Lib & Cons & Lib & Cons & Lib & Cons & Lib & Cons \\
\hline Challenges of the activity (9) & 3.61 & 2.71 & 4.12 & 3.92 & 2.79 & 2.99 & 4.94 & 4.78 \\
\hline Skills in the activity (9) & 7.40 & 7.33 & 7.05 & 6.24 & 7.69 & 7.21 & 6.60 & 6.41 \\
\hline Activity difficult (9) & 3.57 & 2.12 & 3.69 & 3.39 & $2.46 * *$ & $2.96 * *$ & 4.64 & 3.27 \\
\hline Succeeding (9) & $7.38 *$ & $7.90 *$ & $7.39 *$ & $6.83^{*}$ & $7.23 * *$ & $6.79 * *$ & $6.75^{* *}$ & $7.54 * *$ \\
\hline Wish doing something else (9) & $4.86 *$ & $5.79 *$ & 5.05 & 5.16 & 4.42 & 4.07 & 6.21 & 5,22 \\
\hline Living up to others' expectation (10) & $6.94 * *$ & $6.86 * *$ & $7.60 * *$ & $5.37 * *$ & 7.17 & 5.22 & $7.50 *$ & $6.76^{*}$ \\
\hline Not self-conscious or embarrassed (10) & $9.32 * *$ & $6.45^{* *}$ & 9.19 & 7.81 & 9.58 & 8.10 & $9.08 * *$ & $9.10 * *$ \\
\hline
\end{tabular}

Table 6: Significance for ANOVA with interactions: ${ }^{*} \mathrm{P} \leq 0.05,{ }^{*} \mathrm{P} \leq 0.01$. Word pair opposites on a 7-point scale. All other items on a 9 or 10-point scale with 9 and 10 indicating strong positive agreement. 
Figure 1: Who they spend time with, Means by denominational group

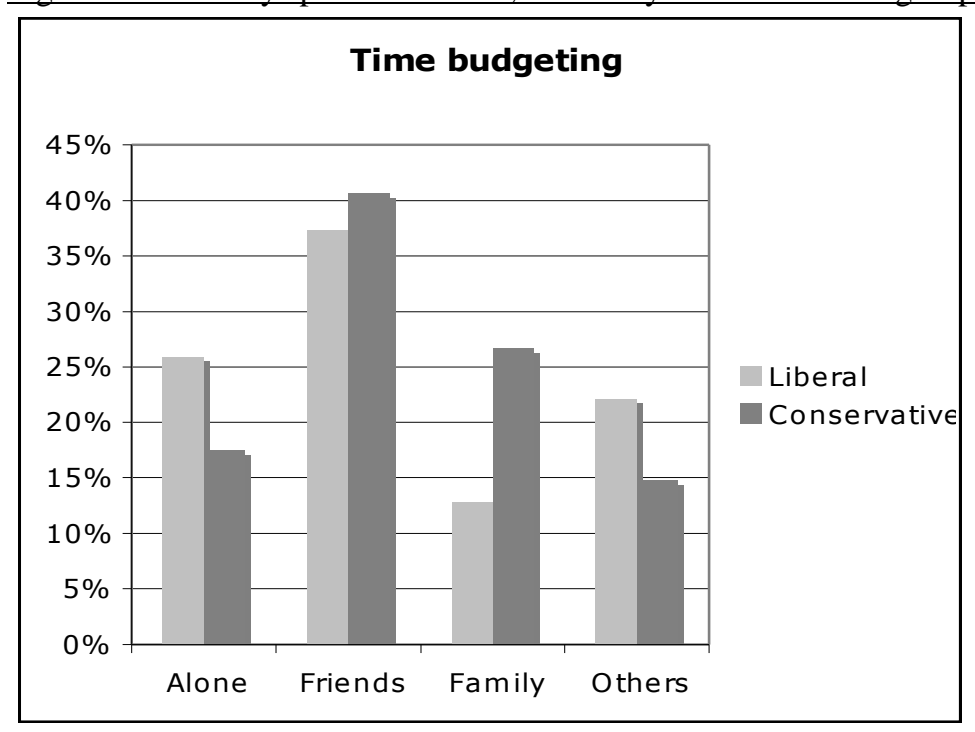


Figure 2a-e: Alone vs. Not alone - Mean values by denominational group

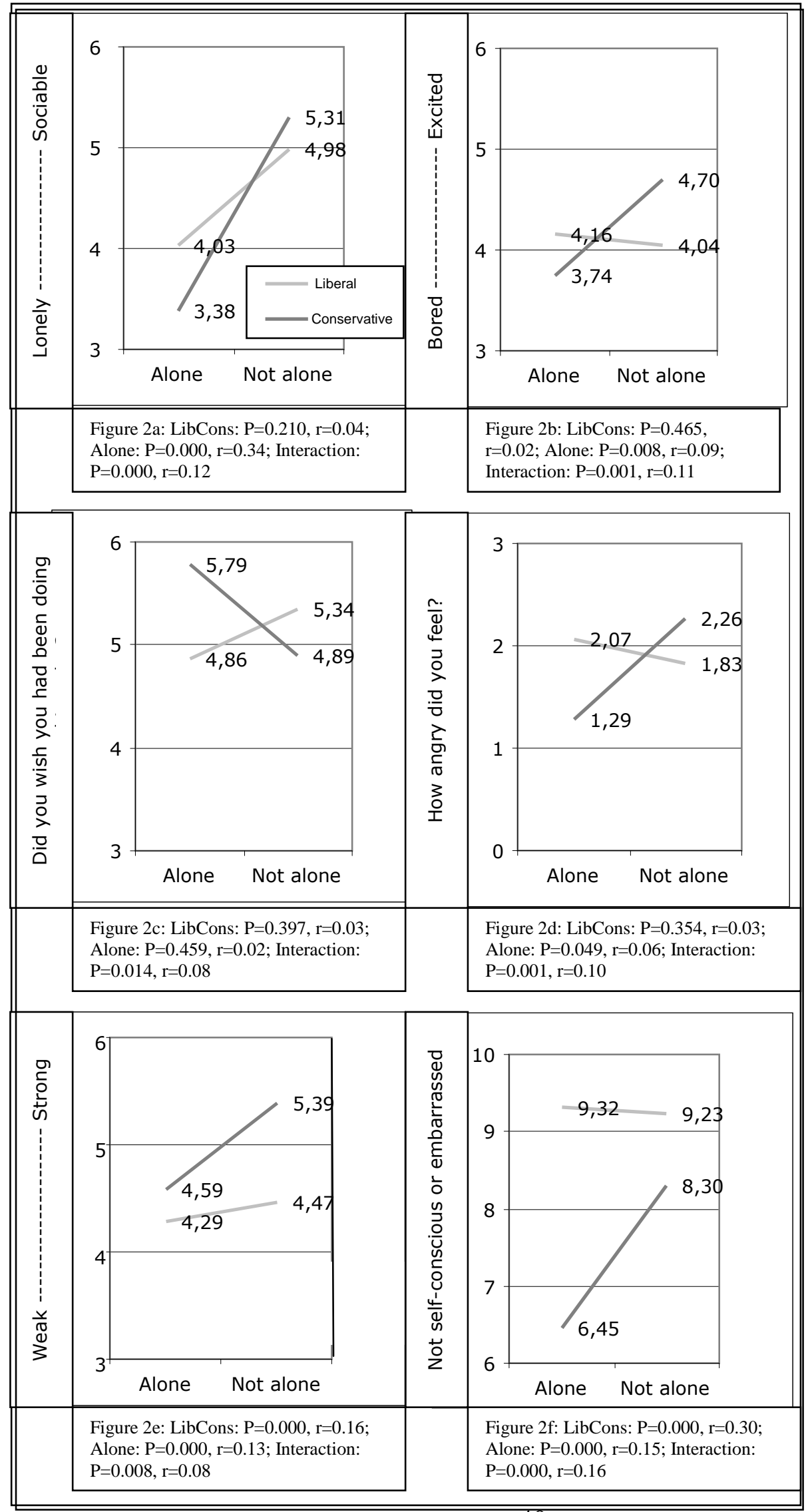


Figure 3: Independent decisions vs. stress by denominational group

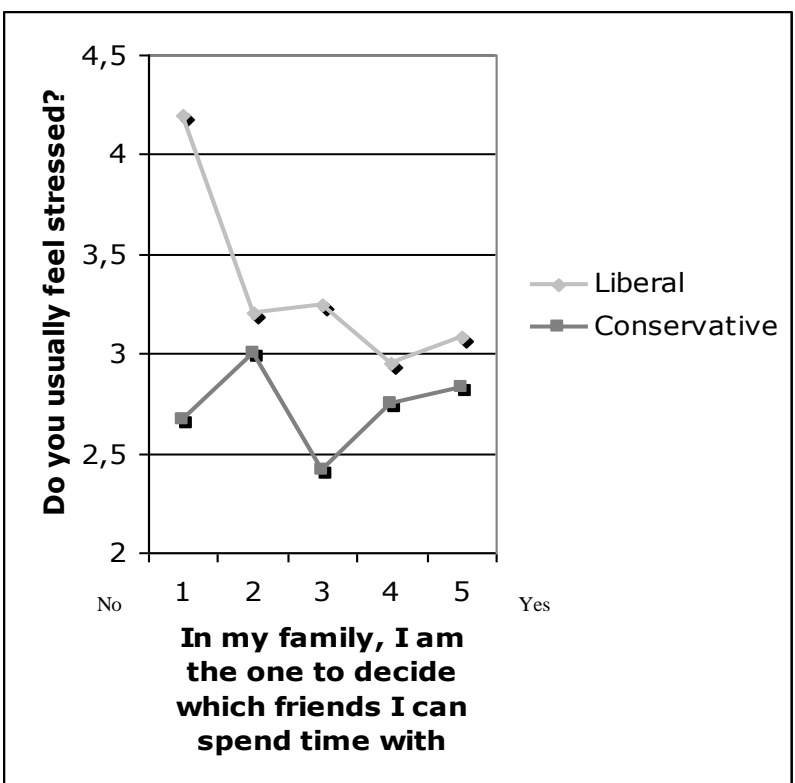

Two-factor ANOVA, Main effects: Stress: $\mathrm{P}=0.0047, \mathrm{r}=0.20$, Decide friends: $\mathrm{P}=0.0006, \mathrm{r}=0.24$, Interaction effects: $\mathrm{P}=0.0230, \mathrm{r}=0.16)$ 
Figure 4: Religiosity vs. diverse opinions by denominational group

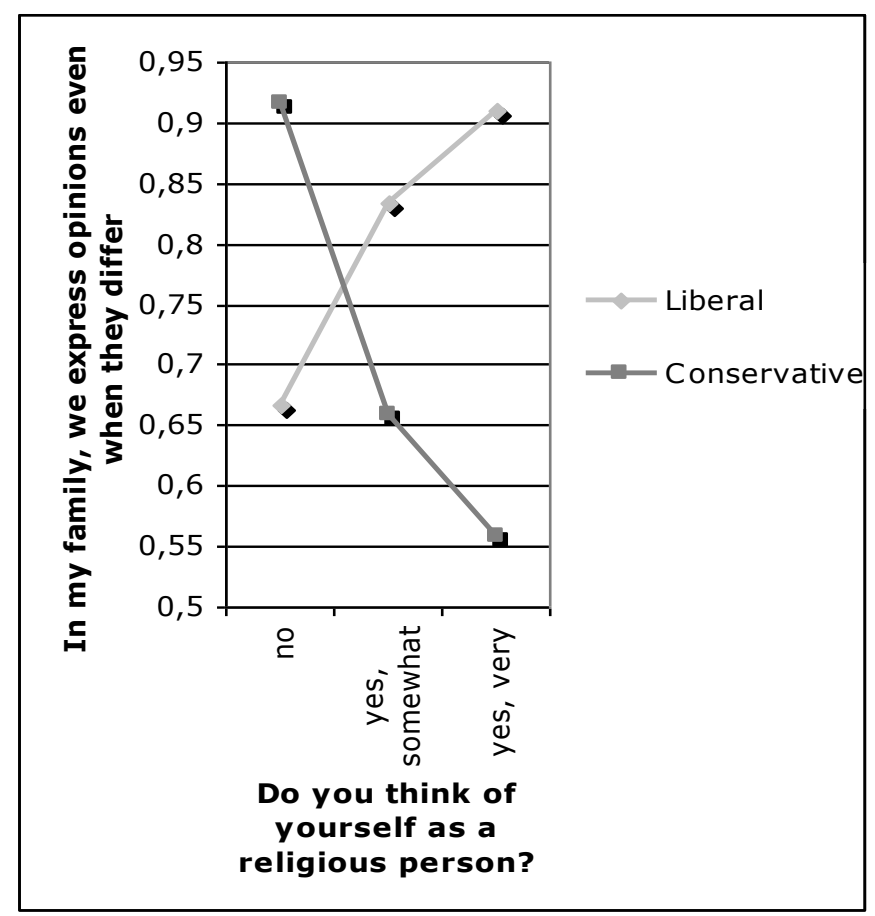

Two-factor ANOVA, Express opinions: $\mathrm{P}=0.0251, \mathrm{r}=0.14$; Religiosity: $\mathrm{P} \leq 0.0001, \mathrm{r}=0.30$; Interaction effects: $\mathrm{P}=0.0012, \mathrm{r}=0.22$ 
Figure 5a-c: Liberal family scale

\section{Items in liberalism scale:}

In my family, ...

I get special attention and help if I have a problem

I am made to feel special on birthdays and holidays

individual accomplishments are noted

I am the one to decide which friends I can spend time with

I am the one to decide whether I can date?

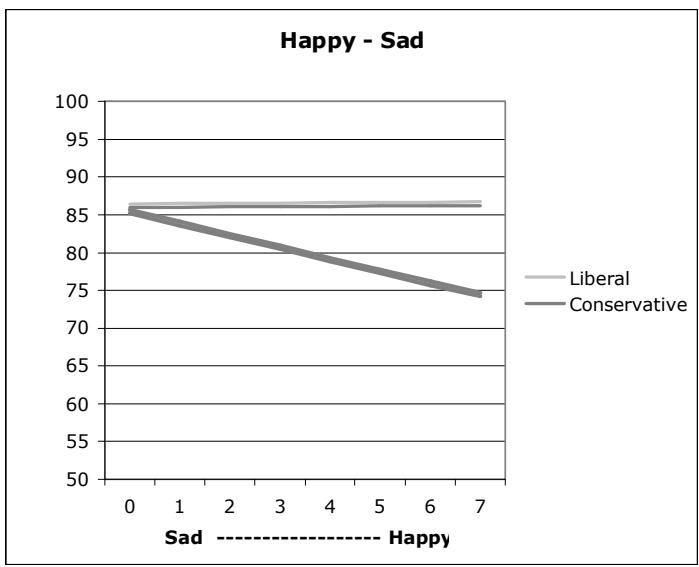

Figure 5b: Two-factor ANOVA, Libsc: $\mathrm{P}=0.0301$

Happy: $\mathbf{P} \leq 0.0001$, Interaction: $\mathrm{P} \leq 0.0001$

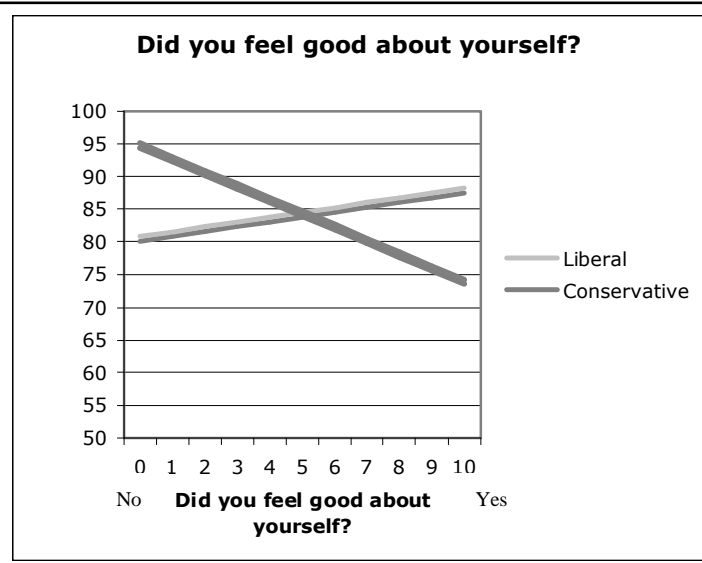

Figure 5a: Two-factor ANOVA, Libsc: $\mathrm{P} \leq 0.0001$, Good: $\mathrm{P} \leq 0.0001$, Interaction: $\mathrm{P} \leq 0.0001$

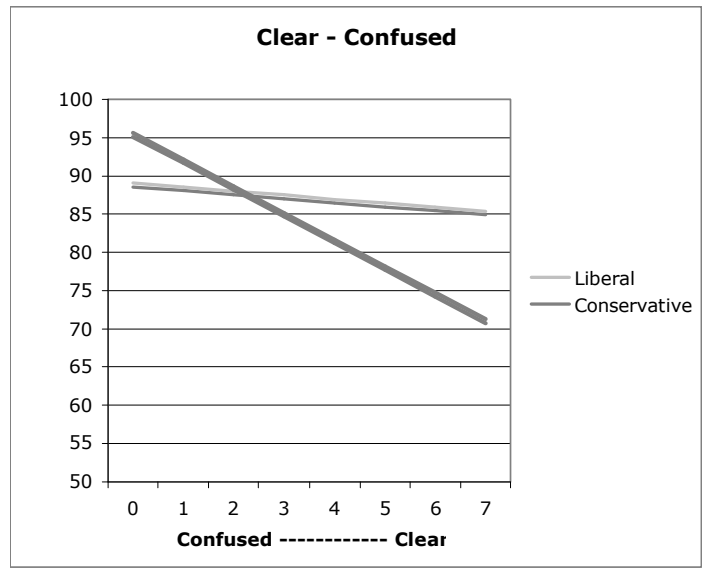

Figure 5c: Two-factor ANOVA, Libsc: $\mathrm{P} \leq 0.0001$, Clear: $\mathrm{P} \leq 0.0001$, Interaction: $\mathrm{P} \leq 0.0001$, 